\title{
Transport Network Design Problem UNDER UnCERTAinty: A ReVIEW AND NEW DEVELOPMENTS
}

Anthony Chen ${ }^{*+}$, Zhong Zhou ${ }^{* *}$, Piya Chootinan ${ }^{+}$, Seungkyu Ryu ${ }^{*}$, Chao Yang ${ }^{++}$, S.C. Wong ${ }^{++}$

* Department of Civil and Environmental Engineering, Utah State University, Logan, UT 843224110, USA

${ }^{* *}$ Citilabs, Tallahassee, Florida 32303, USA

${ }^{+}$Bureau of Planning, Department of Highways Bangkok 10400, Thailand

${ }^{++}$Key Laboratory of Road and Traffic Engineering, Tongji University, Shanghai 201804, P. R. China

${ }^{+++}$Department of Civil Engineering, The University of Hong Kong, Pokfulam Road, Hong Kong, P.R. China

ABSTRACT This paper aims to provide a state-of-the-art review of the transport network design problem (NDP) under uncertainty and to present some new developments on a biobjective reliable network design problem (BORNDP) model that explicitly optimizes the capacity reliability and travel time reliability under demand uncertainty. Both are useful performance measures that can describe the supply-side reliability and demand side reliability of a road network. A simulation-based multi-objective genetic algorithm (SMOGA) solution procedure, which consists of a traffic assignment algorithm, a genetic algorithm, a Pareto filter, and a Monte-Carlo simulation, is developed to solve the proposed BORNDP model. A numerical example based on the capacity enhancement problem is presented to demonstrate the tradeoff between capacity reliability and travel time reliability in the NDP. 


\section{Introduction}

Reliability is generally defined as the probability that the system of interest has the ability to perform an intended function or goal. Recently, the reliability of transport networks has emerged as an important topic due to its critical status as the most important lifeline in the restoration process following the occurrence of a disaster. It has attracted many researchers to develop various indicators to assess the reliability of transport networks (see the recently edited books, proceedings, and special issues by Lam (1999), Bell and Cassir (2000), Bell and Iida (2003), Nicholson and Dantas (2004), Sumalee and Kurauchi (2006a), van Zuylen (2007), Kurauchi and Sumalee (2008), Schmocker and Lo (2009), and Levinson et al. (2010)). From the literature, three main aspects have been considered: (1) connectivity reliability, (2) travel time reliability, and (3) capacity reliability. These three reliability indicators are briefly described below. For other recently proposed transportation reliability measures, see Heydecker et al. (2007) for a review.

- Connectivity reliability is concerned with the probability that network nodes are connected. A special case of connectivity reliability is the terminal reliability which concerns the existence of a path between a specific O-D pair (Iida and Wakabayashi, 1989).

- Travel time reliability is concerned with the probability that a trip between a given O-D pair can be made successfully within a given time interval and a specified level of service (Asakura and Kashiwadani, 1998; Bell et al., 1999).

- Capacity reliability refers to the probability that the network capacity can accommodate a certain volume of traffic demand at a required service level (Chen et al., 1999, 2000, 2002b).

The aim of this paper is twofold: (1) to provide a state-of-the-art review on the transport network design problem (NDP) under uncertainty, and (2) to incorporate the recent emerging development of reliability analysis into the NDP. Recently, Chootinan et al. (2005b) proposed a new capacity reliability index as a surrogate for determining the optimal capacity enhancements to maximize network capacity under day-to-day route choice variability in the stochastic NDP model. This new index explicitly accounts for the probability that all of the network links are 
operated below their capacities when serving different traffic patterns deviating from the average condition (i.e., minimizing the probability of link failures). It is considered as a supply-side measure more useful for the planners. Yang et al. (2000) suggested that synthesizing capacity reliability and travel time reliability together could provide a valuable tool for designing reliable transport networks. In this paper, we extend the reliable NDP model to include the travel time reliability index - a demand-side measure that is more useful to the network users. Hence, the purpose of this paper, in addition to reviewing the state-of-the-art transport NDP under uncertainty, is to present some new developments on a bi-objective reliable NDP (BORNDP) model that explicitly optimizes both supply-side and demand-side reliability measures with demand uncertainty. To our best knowledge, this is the first time that a bi-objective reliable NDP model is being proposed to consider the tradeoff between capacity reliability and travel time reliability.

The organization of this paper is as follows. Section 2 provides a review of the transport NDP under uncertainty. Section 3 presents the model formulation of the BORNDP. Section 4 describes a solution procedure for solving the proposed reliable NDP model. Section 5 provides numerical results for examining the performance of the solution procedure and the tradeoff between capacity reliability and travel time reliability of the non-dominated solutions. Finally, concluding remarks are provided in Section 6.

\section{Review of network design under uncertainty}

Sources of uncertainty exist in both supply side (roadway capacity variation) and demand side (travel demand fluctuation). Examples of supply side uncertainty include weather conditions, traffic incidents, work zones and construction activities, traffic management and control, while examples of demand side uncertainty include temporal variation (e.g., time of day, day of week, or seasonal effects), special events, population characteristics (e.g., age, car ownership, household income, etc.), and traveler information. All these factors contribute to capacity variation and demand fluctuation. The current practice of roadway network design does not account for uncertainty (Yang and Bell, 1998). The reason is the lack of suitable reliability and uncertainty analysis for road networks. The design of a new road network or the upgrading of existing roadways would require a good understanding of the uncertainty involved and the impact on the system-wide performance and the benefit derived from road improvements to the 
network users. Thus it is important to study the uncertainty of road networks such that costeffective and equitable design can be implemented to improve its level of performance from the view point of both the planner and the users. To account for uncertainty, a few recent studies consider various sources of uncertainty in the transport NDP and propose different criteria to hedge against the uncertainty. Table 1 provides a summary of these recent transport NDP models under uncertainty. These models are briefly discussed below; an appendix is provided for readers interested in the general mathematical formulations.

\section{Expected value model}

The expected value model (EVM) is perhaps the most commonly used method for handling uncertainty. The main idea is to optimize the expected value of a linear (or additive) system-wide objective function subject to the budget constraint and the limit constraints on the decision variables. Yin and Ieda (2002) used a user satisfaction reliability measure to determine optimal improvement scheme that involves increasing the capacity or decreasing the variability of travel time for some links in the network. Chen and Yang (2004) provided a NDP model under demand uncertainty that minimizes the expected total travel time subject to spatial equity constraint. Chen and Subprasom (2007) provided a tolling strategy under demand uncertainty for optimizing the expected value of profit, social welfare, and/or equity for build-operate-transfer (BOT) roads. Ukkusuri and Patil (2010) presented a multi-period network design problem that explicitly considers both demand uncertainty and demand elasticity to obtain optimal capacity improvements by staging the investment over time, while Chow and Regan (2011) developed two network-based real option models to consider the design variables, timing of investment decisions, and project selections under time dependency and uncertainty (i.e., the first model is the network option design problem, which maximizes the expanded net present value of a network investment, and the second model is the project selection problem, which decomposes the network investment deferral option into individual, interacting link or project investments).

\section{Mean-variance model}

The mean-variance model is a classical model developed by Markowitz (1927) in the finance area. The basic assumption is that risk is measured by variance, and the decision criteria (or 
objectives) are to maximize the expected return and to minimize the variance of return. In transportation, it has been applied to design reliable/robust network under uncertainty. Chen et al. (2003b) adopted this model for determining the optimal toll and capacity in BOT scheme under demand uncertainty. The mean-variance model involves maximizing the expected profit and minimizing the variance (or standard deviation) of profit. The variance associated with profit is considered as a risk. Subsequently, Chen et al. (2006b), Karroonsonntawong and Waller (2007); Ukkusuri et al. (2007), Ng and Waller (2009), Sumalee et al. (2009), Sharma et al. (2009), and Yin et al. (2009) also applied different versions of the mean-variance model to the capacity enhancement problem under demand uncertainty, while Li et al. (2008) applied the mean-standard deviation model to the toll design under both demand and supply uncertainty, and Gardner et al. (2008) determined the first-best robust pricing scheme using a mean-variance model under demand uncertainty. Some focus on model development for a particular NDP (e.g., Karroonsonntawong and Waller (2007) developed a robust dynamic continuous network design problem that accounts for short-term traffic dynamics using a cell transmission model and longterm O-D demand uncertainty; $\mathrm{Ng}$ and Waller (2009) developed a convex mean-variance model with implicit chance constraints to probabilistically guarantee the obtained capacity expansion decisions satisfy certain system-wide travel time requirement; Yin et al. (2009) provided two models (sensitivity-based and scenario-based) for optimizing the efficiency and robustness (i.e., variance) of the network), while others focus on developing solution techniques to generate a portfolio of Pareto optimal solutions (e.g., Chen et al. (2006b) developed a simulation-based multi-objective genetic algorithm (SMOGA) procedure for solving the BOT network design problem, while Sharma et al (2009) developed a nondominated sorting genetic algorithm (NSGA) to generate the Pareto optimal front for the capacity enhancement problem).

\section{Chance constrained model}

The chance constrained model (CCM), originally developed by Charnes and Cooper (1959), models stochastic decision systems with the assumption that the constraints will hold at least $\alpha$ times, where $\alpha$ is referred to as the confidence level provided as an appropriate safety margin by the decision-maker. Its focus is on the system's ability to meet the chance constraints (risk measures) with a certain reliability under uncertainty. In the context of transport NDP, Waller and Ziliaskopoulos (2001) developed a chance-constrained model for the continuous NDP with 
system optimal flow conditions that accounts for traffic dynamics and time-dependent random demands specified as chance constraints; Lo and Tung (2003) formulated a reserve capacity NDP model by considering degradable link capacity as chance constraints; Chen and Yang (2004) considered both spatial equity and demand uncertainty in the capacity enhancement NDP model by formulating the maximal equity ratio as a chance constraint; and Dimitriou and Stathopoulos (2008) adopted the expected value model of CCM to determine reliable stochastic design of road network systems.

\section{Probability model}

The probability model, also known as the dependent chance model in uncertain programming (Liu, 1999), has been recently proposed to solve the stochastic NDP model. For example, Chootinan et al. (2005b) proposed a new capacity-reliability index, which measures the probability that all of the traffic links are operating below their respective capacities, to determine the optimal design to maximize network capacity under day-to-day route choice variability in the stochastic NDP model. Chen et al. (2006a) provided an alternative reserve capacity model by explicitly minimizing the probabilities of link failures for designing timings for a signal-controlled road network. Yim et al. (2011) extended the reliability-based NDP by Chootinan et al. (2005b) to include not only capacity enhancements of the network but also residential and job allocations in the system to form a more comprehensive reliability-based land use and transportation model for the integrated residential and job allocations and transportation network design problem. Sumalee et al. (2006c) suggested maximizing the network total travel time reliability, which is defined as the probability of the network total travel time to be less than a threshold under demand uncertainty. In this paper, we incorporate the recent emerging development of reliability analysis into the NDP by developing a bi-objective reliable NDP model that explicitly considers both capacity reliability and travel time reliability under demand uncertainty.

\section{Min-Max model and alpha reliable model}

Optimizing the worst-case performance can be regarded as a Min-Max model, which is to identify a robust design plan that minimizes the worst-case total travel time under different future demand scenarios. The Min-Max model is known to give a very conservative solution (i.e., 
tradeoff a significant amount of efficiency for reliability since it has to consider the worst-case scenario). Yin et al. (2009) provided a continuous version while Lou et al. (2009) gave a discrete version of the Min-Max model for modeling the capacity enhancement problem under demand uncertainty. On the contrary, the alpha reliable NDP model, proposed by Chen et al. (2007), has the ability to specify a risk control measure through the confidence level $\alpha$ to identify a solution with an acceptable risk without sacrificing too much efficiency. It optimizes the total travel time by considering demand uncertainty for different risk aversion levels. This alpha reliable NDP model has a number of attractive features: (1) it adopts the Value-at-Risk (VaR) risk measure instead of the utility function to model planner risk preferences, (2) the risk preference is specified using the performance measure with some confidence level (planner might find it easier by selecting their own level of risk), (3) VaR is a commonly used risk measure adopted in finance to evaluate the maximum loss with a specified confidence level, and (4) VaR is applicable to non-symmetrical performance distribution, which is suitable to measure downside risk (i.e., losses in the right-hand-side tail).

For a review of the uncertain programs (i.e., expected value model, chance constrained model, and dependent chance model) used to model the transport NDP under uncertainty, readers are referred to Chen et al. (2009) for the single objective models and Chen et al. (2010) for the multiple objective models. 
Table 1. Summary of recent developments in NDP models under uncertainty

\begin{tabular}{|c|c|c|c|c|c|}
\hline Model & Reference & Uncertainty & Design Variable & $\begin{array}{l}\text { Performance } \\
\text { Indicator }\end{array}$ & Approach/Criterion for Hedging Uncertainty \\
\hline \multirow{5}{*}{$\begin{array}{l}\text { Expected } \\
\text { value } \\
\text { model }\end{array}$} & Yin and Ieda, 2002 & Travel time & $\begin{array}{c}\text { Capacity } \\
\text { enhancement and } \\
\text { variability reduction }\end{array}$ & $\begin{array}{l}\text { User satisfaction } \\
\quad \text { reliability }\end{array}$ & Minimizing total travel disutility \\
\hline & Chen and Yang, 2004 & Demand & $\begin{array}{c}\text { Capacity } \\
\text { enhancement }\end{array}$ & Total travel time & $\begin{array}{l}\text { Minimizing the expected total travel time subject to } \\
\text { spatial equity constraint }\end{array}$ \\
\hline & $\begin{array}{l}\text { Chen and Subprasom, } \\
2007\end{array}$ & Demand & Toll & $\begin{array}{l}\text { Profit; social welfare; } \\
\text { equity }\end{array}$ & $\begin{array}{l}\text { Optimizing the expected value of profit, social } \\
\text { welfare, and/or equity }\end{array}$ \\
\hline & $\begin{array}{l}\text { Ukkusuri and Patil, } \\
2010\end{array}$ & Demand & $\begin{array}{c}\text { Capacity } \\
\text { enhancement }\end{array}$ & $\begin{array}{l}\text { System consumer } \\
\text { surplus }\end{array}$ & $\begin{array}{c}\text { Maximize the present expected system consumer } \\
\text { surplus }\end{array}$ \\
\hline & $\begin{array}{l}\text { Chow and Regan, } \\
2011\end{array}$ & Demand & $\begin{array}{l}\text { Capacity } \\
\text { enhancement }\end{array}$ & Option value & $\begin{array}{l}\text { Maximize the expanded net present value of a } \\
\text { network investment by optimizing not only the } \\
\text { design variables but also the timing of the } \\
\text { investment decisions }\end{array}$ \\
\hline \multirow{8}{*}{$\begin{array}{l}\text { Mean- } \\
\text { variance } \\
\text { model }\end{array}$} & $\begin{array}{l}\text { Chen et al., 2003b; } \\
\text { 2006b }\end{array}$ & Demand & $\begin{array}{l}\text { Toll and capacity of } \\
\text { BOT roads }\end{array}$ & Profit; social welfare & $\begin{array}{l}\text { Optimizing the expected value and variance of } \\
\text { profit (or social welfare) }\end{array}$ \\
\hline & $\begin{array}{l}\text { Karroonsonntawong } \\
\text { and Waller, } 2007\end{array}$ & Demand & $\begin{array}{l}\text { Capacity } \\
\text { enhancement }\end{array}$ & Total travel time & $\begin{array}{l}\text { Minimizing the weighted summation of the } \\
\text { expected total system travel time and the expected } \\
\text { risk using dynamic traffic assignment linear } \\
\text { programming models }\end{array}$ \\
\hline & $\begin{array}{l}\text { Ukkusuri et al., 2007; } \\
\text { Sharma et al., } 2009\end{array}$ & Demand & $\begin{array}{c}\text { Capacity } \\
\text { enhancement }\end{array}$ & Total travel time & $\begin{array}{l}\text { Minimizing the total system travel time and the } \\
\text { higher moment for total system travel time }\end{array}$ \\
\hline & Gardner et al., 2008 & Demand & Toll & Total travel time & $\begin{array}{l}\text { Minimizing the expected value and the variance of } \\
\text { the total system travel time }\end{array}$ \\
\hline & Li et al., 2008 & $\begin{array}{l}\text { Demand; } \\
\text { degradable link } \\
\text { capacity }\end{array}$ & Toll & $\begin{array}{l}\text { Network travel time } \\
\text { reliability }\end{array}$ & $\begin{array}{l}\text { Optimizing a weighted sum of the expected value } \\
\text { and standard deviation of trip travel time }\end{array}$ \\
\hline & $\mathrm{Ng}$ and Waller, 2009 & $\begin{array}{l}\text { Degradable link } \\
\text { capacity }\end{array}$ & $\begin{array}{c}\text { Capacity } \\
\text { enhancement }\end{array}$ & Total travel time & $\begin{array}{l}\text { Minimizing the total system travel time while } \\
\text { satisfying certain probabilistic guarantees }\end{array}$ \\
\hline & Sumalee et al., 2009 & $\begin{array}{l}\text { Demand; } \\
\text { route choice }\end{array}$ & $\begin{array}{c}\text { Capacity } \\
\text { enhancement }\end{array}$ & Reserve capacity & $\begin{array}{l}\text { Maximizing a weighted sum of the expected value } \\
\text { and standard deviation of perturbed demands }\end{array}$ \\
\hline & Yin et al., 2009 & Demand & $\begin{array}{c}\text { Capacity } \\
\text { enhancement }\end{array}$ & Total travel time & $\begin{array}{l}\text { Optimizing the efficiency and robustness (i.e., } \\
\text { variance) of the network using sensitivity-based and } \\
\text { scenario-based models }\end{array}$ \\
\hline
\end{tabular}


Table 1. (Continued)

\begin{tabular}{|c|c|c|c|c|c|}
\hline \multirow{4}{*}{$\begin{array}{l}\text { Chance- } \\
\text { constrained } \\
\text { model }\end{array}$} & $\begin{array}{c}\text { Waller and } \\
\text { Ziliaskopoulos, } 2001\end{array}$ & Demand & $\begin{array}{c}\text { Capacity } \\
\text { enhancement }\end{array}$ & Total travel time & $\begin{array}{l}\text { Minimizing the total travel time subject to time- } \\
\text { dependent random demands specified as chance } \\
\text { constraints }\end{array}$ \\
\hline & Lo and Tung, 2003 & $\begin{array}{l}\text { Degradable link } \\
\text { capacity }\end{array}$ & $\begin{array}{c}\text { Capacity } \\
\text { enhancement }\end{array}$ & Reserve capacity & $\begin{array}{l}\text { Maximizing the reserve capacity subject to link } \\
\text { capacity chance constraints }\end{array}$ \\
\hline & Chen and Yang, 2004 & Demand & $\begin{array}{c}\text { Capacity } \\
\text { enhancement }\end{array}$ & Total travel time & $\begin{array}{l}\text { Minimizing the expected total travel time subject to } \\
\text { spatial equity chance constraints }\end{array}$ \\
\hline & $\begin{array}{c}\text { Dimitriou and } \\
\text { Stathopoulos, } 2008\end{array}$ & $\begin{array}{l}\text { Demand; } \\
\text { degradable link } \\
\text { capacity }\end{array}$ & $\begin{array}{c}\text { Capacity } \\
\text { enhancement }\end{array}$ & Total travel time & $\begin{array}{l}\text { Minimizing the expected total travel time subject to } \\
\text { a chance constraint on the total travel time }\end{array}$ \\
\hline \multirow{5}{*}{$\begin{array}{l}\text { Probability } \\
\text { model }\end{array}$} & $\begin{array}{l}\text { Chootinan et al., } \\
2005 \mathrm{~b}\end{array}$ & Route choice & $\begin{array}{c}\text { Capacity } \\
\text { enhancement }\end{array}$ & Capacity reliability & $\begin{array}{c}\text { Maximizing the network capacity (or minimizing } \\
\text { the link failures) }\end{array}$ \\
\hline & Chen et al., 2006a & Route choice & Signal timing & Capacity reliability & $\begin{array}{c}\text { Maximizing the network capacity (or minimizing } \\
\text { the link failures) }\end{array}$ \\
\hline & Sumalee et al., 2006c & $\begin{array}{l}\text { Demand; route } \\
\text { choice }\end{array}$ & $\begin{array}{c}\text { Capacity } \\
\text { enhancement }\end{array}$ & $\begin{array}{l}\text { Total travel time } \\
\text { reliability }\end{array}$ & Maximizing the total travel time reliability \\
\hline & Yim et al., 2011 & Demand & $\begin{array}{c}\text { Capacity } \\
\text { enhancement and } \\
\text { residential and job } \\
\text { allocations }\end{array}$ & Capacity reliability & $\begin{array}{c}\text { Maximizing the network capacity (or minimizing } \\
\text { the link failures) }\end{array}$ \\
\hline & This paper & Demand & $\begin{array}{c}\text { Capacity } \\
\text { enhancement }\end{array}$ & $\begin{array}{c}\text { Capacity reliability } \\
\text { and travel time } \\
\text { reliability }\end{array}$ & $\begin{array}{l}\text { Maximizing both capacity reliability and travel time } \\
\text { reliability }\end{array}$ \\
\hline \multirow{2}{*}{$\begin{array}{l}\text { Min-max } \\
\text { model }\end{array}$} & Lou et al., 2009 & Demand & $\begin{array}{c}\text { Discrete capacity } \\
\text { enhancement }\end{array}$ & Total travel time & $\begin{array}{l}\text { Minimizing the maximum system travel cost } \\
\text { realized from the uncertainty set of future demand }\end{array}$ \\
\hline & Yin et al., 2009 & Demand & $\begin{array}{c}\text { Capacity } \\
\text { Enhancement }\end{array}$ & Total travel time & Minimizing the worst-case total travel time \\
\hline $\begin{array}{l}\text { Alpha } \\
\text { reliable } \\
\text { model }\end{array}$ & Chen et al., 2007 & Demand & $\begin{array}{c}\text { Capacity } \\
\text { enhancement }\end{array}$ & $\begin{array}{l}\text { Total travel time } \\
\text { budget }\end{array}$ & $\begin{array}{l}\text { Minimizing the total travel time budget required to } \\
\text { satisfy the total travel time reliability constraint }\end{array}$ \\
\hline
\end{tabular}




\section{Model formulation}

This section describes the bi-objective reliable network design problem (BORNDP) as a dependent chance multi-objective programming (DCMOP) model (Liu, 1999) in a bi-level programming framework for the optimal capacity enhancement problem with demand uncertainty.

\section{Reliability Measures}

In this paper, we consider the bi-objective reliable NDP model, where the design variables (u) are the link capacity enhancements. In the capacity enhancement NDP model, the upper-level subprogram determines the optimal capacity enhancements (u) in a transportation network by optimizing a vector of system-wide objectives with demand uncertainty $(\mathbf{Q})$, while the lowerlevel subprogram determines the route choice behavior of network users for a given capacity enhancement with demand uncertainty $(\mathbf{v}(\mathbf{u}, \mathbf{Q}))$. The system-wide objective functions are to maximize both capacity reliability (a supply-side performance measure) and travel time reliability (a demand-side performance measure). These two reliability measures are discussed in the following sections.

Capacity reliability. Conventional capacity reliability analysis utilizes the concept of reserve capacity that was originally applied to the isolated junctions (Webster and Cobbe, 1966; Allsop, 1972; Wong, 1996) and was then extended to the signal-controlled road networks (Wong and Yang, 1997). Using the concept of reserve capacity of a road network, Chen et al. (1999) defined capacity reliability as the probability that the network capacity can accommodate a certain volume of traffic demand at a required service level. Chen et al. (2002b) provided an assessment methodology, which combines the reliability and uncertainty analysis, network equilibrium models, sensitivity analysis of the equilibrium network-flow and the expected performance measure, as well as Monte Carlo methods, to assess the capacity reliability of a degradable road network. Chen et al. (2000) also examined the effects of route choice models on assessing network capacity reliability. Sumalee and Kurauchi (2006b) adopted the capacity reliability concept to evaluate traffic regulation strategies after a major disaster. Lo and Tung (2003) studied the problem of allocating design capacities to maximize the multiplier of the O-D demand matrix (i.e., network reserve capacity), subject to the probabilistic user-equilibrium (PUE) constraints on network links and the budgetary 
constraint. Recently, Chootinan et al. (2005) proposed an alternative capacity reliability index, which measures the probability that all of the network links are operating below their respective capacities under the day-to-day route choice variability, as a surrogate for determining the optimal design variables to maximize network capacity in a reliability-based NDP model. Unlike the original capacity reliability index proposed by Chen et al. (1999), the new capacity reliability index explicitly maximizes the probability that all of the network links are operated below their capacities when serving different traffic patterns deviating from the average condition (i.e., or minimizes link failures).

Let $v_{a}(\mathbf{u}, \mathbf{Q})$ and $C_{a}\left(u_{a}\right)$ be respectively the flow and capacity of link $a$. Both the link flow and link capacity are a function of the design variables (i.e., capacity enhancements). Here the link flow is also a random variable, where the randomness is induced by the random demand vector $\mathbf{Q}$. Hence, the probability of all network links operating below their capacities defines the capacity reliability index:

$$
R_{C R}=\operatorname{Pr}\left(v_{a}(\mathbf{u}, \mathbf{Q}) \leq C_{a}\left(u_{a}\right), \forall a \in A\right) .
$$

This capacity reliability index can be interpreted as a supply-side measure that minimizes the probability of link failures. It also serves as a surrogate for determining the adequacy of the network capacity in accommodating the required travel demand at a specified level of service.

Travel time reliability. On the other hand, network users might be more concerned about the reliability of getting to their respective destinations on time. In transportation network reliability analysis, this measure is known as travel time reliability, which is the probability that a trip between a given origin-destination (O-D) pair can be made successfully within a given time interval and at a specified level-of-service (Asakura and Kashiwadanu, 1991; Bell et al., 1999; Chen et al., 2002a, 2003a). There are two potential measures - path travel time reliability and O-D travel time reliability - that are of interest to the travelers and the network planner. Path travel times are computed by summing up the link travel time on a given route. For the O-D travel times, they are computed as a weighted average of the path travel times, where the weights are the path flows.

- Path travel time reliability is defined as the probability that the travel time of a given path is within an acceptable threshold. 
- O-D travel time reliability is defined as the probability that the weighted average travel time of a given O-D pair is within an acceptable threshold.

Travelers are more concerned about the path travel time reliability, because it directly affects their route choice decisions. O-D travel time reliability measures all relevant paths used by travelers to define an aggregate measure for the level-of-service between a given O-D pair. It can be used as a proxy to evaluate the performance of a given O-D pair (i.e., O-D sub-system reliability in terms of travel time). Thus, the probability of all O-D travel times operating below their respective thresholds defines the travel time reliability index:

$$
R_{T T R}=\operatorname{Pr}\left(T_{w}(\mathbf{u}, \mathbf{v}(\mathbf{u}, \mathbf{Q})) \leq t_{w}, \forall w \in W\right),
$$

where $T_{w}(\mathbf{u}, \mathbf{v}(\mathbf{u}, \mathbf{Q}))$ is the travel time between O-D pair $w$ (i.e., a random variable), and $t_{w}$ is a threshold value between O-D pair $w$ specified by the network users.

\section{Mathematical Formulation}

This paper considers both supply-side reliability and demand-side reliability with different levels of service as a bi-objective reliable NDP (BORNDP) model. Hence, the problem is to determine the optimal capacity enhancements for a given combination of level of service requirement by maximizing the probability of all network links operating below their capacities (i.e., capacity reliability) as a supply-side measure and by maximizing the probability of on-time arrivals (i.e., travel time reliability) for network users from all O-D pairs as a demand-side measure subject to the budget constraint and design variable constraints, while taking into account the behavior of network users and demand uncertainty. The problem can now be posed as a special case of the stochastic multi-objective bi-level programming (SMOBLP) formulation (Liu, 1999).

The upper-level subprogram can be formulated as a dependent chance bi-objective programming problem as follows.

$$
\max _{\mathbf{u}}\left\{\begin{array}{r}
R_{\mathrm{CR}}=\operatorname{Pr}\left(v_{a}(\mathbf{u}, \mathbf{Q}) \leq \phi_{s} C_{a}\left(\mathrm{u}_{\mathrm{a}}\right), \forall a \in A\right) \\
R_{\mathrm{TTR}}=\operatorname{Pr}\left(T_{w}(\mathbf{u}, \mathbf{v}(\mathbf{u}, \mathbf{Q})) \leq \pi_{s} t_{w}, \forall w \in W\right)
\end{array}\right\}
$$

subject to

$$
\sum_{a \in A} g\left(u_{a}\right) \leq B,
$$




$$
0 \leq u_{a} \leq u_{a}^{\max }, \quad \forall a \in \bar{A},
$$

where $\phi_{s}$ and $\pi_{s}$ are threshold values defining the level-of-service (LOS) for supply-side reliability and demand-side reliability, respectively; $\bar{A}$ is the set of capacity enhancement links in the network; $g_{a}\left(u_{a}\right)$ is the construction cost function of link $a ; B$ is the budget; and $u_{a}^{\max }$ is the upper bound of capacity enhancement on link $a$; for a realization $\mathbf{q}$ of the random demand $\mathbf{Q}, v_{a}(\mathbf{u}, \mathbf{q})$ is the equilibrium flow on link $a$, which can be obtained by solving the lower-level subprogram as shown below:

$$
\min _{v} \sum_{a \in A} \int_{0}^{v_{a}} t_{a}\left(\omega, u_{a}\right) d \omega
$$

subject to

$$
\begin{gathered}
\sum_{r \in R_{w}} f_{r}^{w}=q_{w}, \quad \forall w \in W, \\
v_{a}=\sum_{w \in W} \sum_{r \in R_{w}} f_{r}^{w} \delta_{a r}^{w}, \quad \forall a \in A, \\
f_{r}^{w} \geq 0, \quad \forall r \in R_{w}, w \in W .
\end{gathered}
$$

The objective function (3a) is to optimize both supply-side reliability and demand-side reliability for a given combination of levels of service $\left(\phi_{\mathrm{s}}\right.$ and $\left.\pi_{\mathrm{s}}\right)$ by maximizing the probability of all network links operating below their capacities (i.e., capacity reliability) and the probability of all O-D travel times operating below their respective thresholds (i.e., travel time reliability). Constraint (3b) is the budgetary constraint. Constraint (3c) sets the lower and upper bounds of the possible link capacity enhancements. Equation (4a) is the objective function for the user-equilibrium problem (i.e., the sum of the integrals of the link cost function), equation (4b) is the flow conservation constraint, equation (4c) represents the linkpath flow relationship, and equation (4d) ensures the non-negativity of path flows.

For a given realization $\mathbf{q}$, the optimal solution $\mathbf{f}^{*}=\left(\ldots, f_{r}{ }^{w}, \ldots\right)^{T}$ to the lower-level subprogram satisfies the following user equilibrium (UE) conditions:

$$
C_{r}^{w}\left(\mathbf{f}^{*}\right)-T_{w}\left(\mathbf{f}^{*}\right)\left\{\begin{array}{ll}
=0 & \text { if } f_{r}^{w}>0 \\
\geq 0 & \text { if } f_{r}^{w}=0
\end{array}, \quad \forall r \in R_{w}, w \in W,\right.
$$


where $C_{r}^{w}\left(\mathbf{f}^{*}\right)=\sum_{a} t_{a}\left(v_{a}, u_{a}\right) \delta_{a r}^{w}$ is the travel time on path $r \in R_{w}$ between the O-D pair $w \in W$, and $T_{w}\left(\mathbf{f}^{*}\right)=\min \left\{C_{r}^{w}\left(\mathbf{f}^{*}\right), \forall r \in R_{w}\right\}$ is the minimum travel time between the O-D pair $w \in W$. That is, when the travel time on path $r$ is larger than or equal to the minimum travel time, the flow on that path is zero or the path is not used. When the travel time on path $r$ is equal to the minimum, its flow is greater than zero or the path is used. For simplicity, this widely used UE model is used as the lower-level subprogram to model users' route choice behavior for each realization of O-D demand (i.e., route choice pattern will settle into a full UE). We further assume that there is a mechanism (e.g., four-step travel demand forecasting model or activity-based travel demand forecasting model) to predict the future demand with some levels of uncertainty. To ensure a reliable network design, we may plan for the worst, but it would be generally too costly. To compromise, we design a system that is robust enough to entertain the majority of cases that deviate from the predicted future demand. Putting this into context, if we tolerate a 5\% level in the parameter specification, it means that out of every 100 possibilities away from the predicted demand, there are only 5 cases that the designed system cannot accommodate the realized demand in terms of the specified capacity and travel time thresholds. Therefore, for each realized demand, we can allow the system to go into a complete UE, because this realized demand will last for a sufficiently long time for the system to evolve into the final UE pattern. This BORNDP model can be considered as a strategic planning application.

\section{Solution procedure}

Stochastic bi-level programs with multiple objectives are generally difficult to solve by traditional calculus-based optimization methods. To solve the BORNDP model with demand uncertainty, we develop a simulation-based multi-objective genetic algorithm (SMOGA) solution procedure to handle the different complexities involved in solving the BORNDP model in this paper. The SMOGA solution procedure consists of a traffic assignment algorithm, a genetic algorithm, a Pareto filter, and a Monte-Carlo simulation. The demand uncertainty is addressed by the stochastic (Monte Carlo) simulation. The nonlinear and nonconvex nature of the bi-level program is handled by the genetic algorithm (Gen and Cheng, 2000). Bi-level mathematical programs are generally difficult to solve because evaluation of the upper-level objective function requires solving the lower-level subprogram. 
Here a standard traffic assignment algorithm (known as the Frank-Wolfe algorithm) is used to solve the lower-level subprogram (Sheffi, 1985). When the objectives are conflicting, there is, in general, no single optimal solution that can simultaneously optimizes all aspects. A solution may be best in one objective, but worst in the others. Hence, solving multi-objective optimization problems often requires a set of non-dominated (ND) solutions, not just a single best solution as in the single objective optimization problems. The distance-based method (Osyczka and Kundu, 1995) is used as a Pareto filter to determine a set of ND solutions. Here the main steps of the SMOGA solution procedure for solving the BORNDP model as depicted in Figure 1 are summarized.

Step 1. Define GA parameters: mutation probability $\left(P_{m}\right)$, crossover probability $\left(P_{c}\right)$, population size $(P)$, maximum number of generations $(N)$, and maximum number of sample sizes $(S)$. Initialize $n$ (counter for the number of generations) and a set of initial solutions of size $P$. Initialize $p$ (counter for the number of solutions).

Step 2. Evaluate the objective functions (i.e., capacity reliability and travel time reliability for a given combination of supply and demand levels of service) of solution $p$ with the maximum number of samples.

Step 3. Use the distance-based method to update the ND solution set. Increment $p=p+1$. Repeat Step 2 until $p>P$ (population size).

Step 4. Evolve all solutions via GA operators: reproduction, crossover, and mutation. Increment $n=n+1$. Repeat Step 2 and Step 3 until $n>N$.

Step 5. Report the ND solution set. 


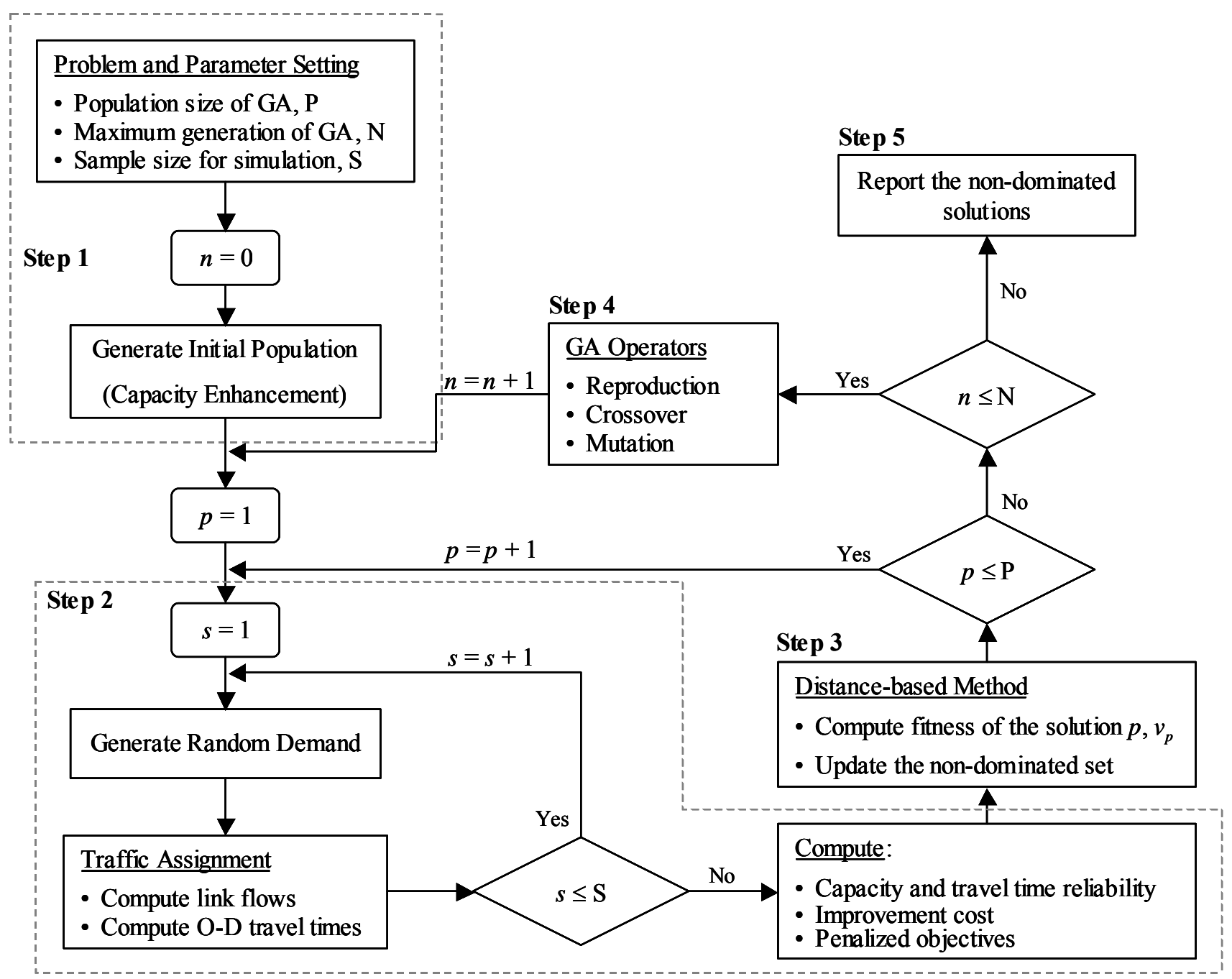

Figure 1. A simulation-based multi-objective genetic algorithm (SMOGA) solution procedure

Remark 1: In Step 2, evaluating the objective functions of each capacity enhancement design vector requires solving the lower-level subprogram to obtain the probability distributions of link flows $v_{a}(\mathbf{u}, \mathbf{Q})$ and O-D travel times $T_{w}(\mathbf{u}, \mathbf{v}(\mathbf{u}, \mathbf{Q}))$ in order to compute the capacity reliability and travel time reliability in the upper-level subprogram. The linkflow pattern and the OD travel time pattern are random variables as a function of the design vector $\mathbf{u}$ and the random demand vector $\mathbf{Q}$. Computing the reliability measures in Eqs. (1) and (2) or Eq. (3a) requires evaluating the joint probability functions of link flow and O-D travel time distributions, which is accomplished by the stochastic simulation.

Remark 2: To update the $N D$ solutions from one generation to the next in Step 3, the distance-based method (Osyczka \& Kundu, 1995) is used as a Pareto filter to sort out the solutions that go into an approximate Pareto solution set. The main idea is to evolve the 
genetic search toward the ideal Pareto solutions in which all individual objectives are simultaneously achieved at the highest possible level. In practice, such a solution is usually unknown; therefore, an alternative benchmark, which is the current set of ND solutions, is considered. The solutions are improved by being distanced away from the existing set of $N D$ solutions. It should be noted that the SMOGA solution procedure can accommodate any Pareto filter methods (e.g., non-dominated sorting genetic algorithm (NSGA) II (Deb. et al., 2002)) to update the approximate Pareto solution set.

Remark 3: In Step 4, the main purpose is to perform the GA operators (i.e., reproduction, crossover, and mutation) to evolve the chromosomes (or design variables) to obtain better solutions. Detailed descriptions of the GA implementation can be found in Gen \& Cheng (2000).

For a detailed description of the SMOGA solution procedure, the reader may refer to Chen et al. (2006b, 2010).

\section{Numerical example}

Problem description and GA parameter setting

In this section, we illustrate the BORNDP model with a simple network given in Figure 2. The network consists of six nodes, seven links, two origins, two destinations, and four O-D pairs. The link travel time function used is the standard Bureau of Public Road (BPR) function:

$$
t_{a}=t_{a}^{f}\left(1+0.15\left(\frac{v_{a}}{C_{a}}\right)^{4}\right)
$$

where $v_{a}, t_{a}^{f}$, and $C_{a}$ are the flow, free-flow travel time, and capacity on link $a$, respectively. 


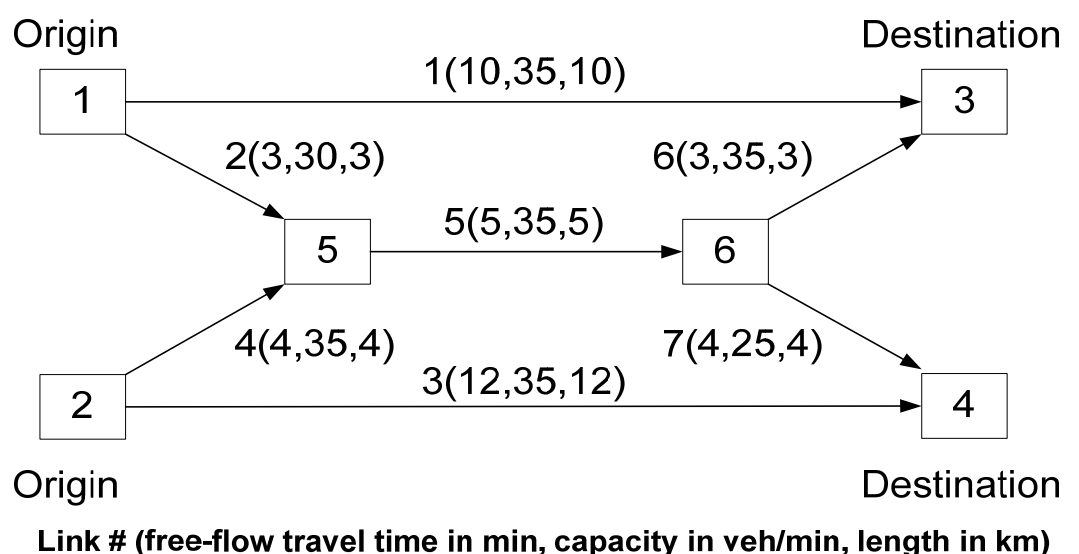

Figure 2. Test network

In the experiment, it is assumed that the demands of O-D pairs $(1,3),(1,4),(2,3)$, and $(2,4)$ are normally distributed with the means of $36,9,9$, and $36 \mathrm{veh} / \mathrm{min}$, respectively, while the standard deviations are one-third of the mean values. Alternatively, these random O-D demands can be generated by a random multivariate generation procedure (e.g., Chen et al., 2002b), which is capable of generating multivariate, non-normal, correlated random variables. Link capacity is allowed to upgrade up to $100 \%$ of its existing capacity. The construction-cost function adopted in this study is

$$
g\left(u_{a}\right)=0.3 \cdot u_{a} \cdot L_{a}
$$

where $u_{a}$ is the capacity expansion of link $a$ and $L_{a}$ is the length of link $a$. The definitions of level of service (LOS) for both supply side and demand side are listed in Table 2. For each budget level, there are 16 possible combinations of the supply-side (i.e., capacity reliability) and demand-side (i.e., travel time reliability) LOS that can be considered for the capacity enhancements. For example, (C, D) means LOS "C" for supply side and LOS "D" for demand side, (E, F) means LOS “E” for supply side and LOS "F” for demand side, and so on. 
Table 2. Level of service for supply side and demand side of road network

\begin{tabular}{ccc}
\hline Level of Service & $\begin{array}{c}\text { Supply Side }\left(\phi_{\mathrm{s}}\right) \\
\text { V/C ratio }\end{array}$ & $\begin{array}{c}\text { Demand Side }\left(\pi_{\mathrm{s}}\right) \\
t_{c} / t_{f} \text { ratio }^{\mathrm{a}}\end{array}$ \\
\hline LOS "A" and LOS "B" & $\leq 0.50$ & $\leq 1.010$ \\
LOS "C" & $>0.50-0.75$ & $>1.010-1.050$ \\
LOS "D" & $>0.75-0.85$ & $>1.050-1.080$ \\
LOS "E" & $>0.85-1.00$ & $>1.080-1.150$ \\
LOS "F" & $>1.00$ & $>1.150$ \\
\hline
\end{tabular}

a: $t_{c}$ is the prevailing travel time while $t_{f}$ is the free-flow travel time

Note: $\phi_{\mathrm{s}}$ is set according to the Highway Capacity Manual, while $\pi_{\mathrm{s}}$ is set approximately using the standard BPR link-cost function. Its value corresponds to the $\mathrm{V} / \mathrm{C}$ ratio of the supply side.

This study used the following parameters:

- Population size $=128$

- Maximum number of generations $=1000$

- Arithmetic crossover with half replacement strategy

- Mutation rate $=0.20$

- Sample size of random demand $=1000$.

These parameters for testing the SMOGA solution procedure were selected based on some numerical experiments conducted in Chootinan et al. (2005) and Chen et al. (2006b).

Before discussing the numerical results of the reliability-based capacity enhancement problem, the performance results of the existing network are shown in Tables 3 and 4. Table 3 shows the expected value and standard deviation of link flows, and the probability of link flow operating below its link capacity. Table 4 shows the capacity reliability and travel time reliability measures at different levels of service for the existing network before capacity enhancements. As can be seen from Table 3, links 1, 3, and 5 have a lower probability compared to other links, indicating that these links have a higher probability of link failures and contribute to a lower overall network reliability for both supply side and demand side. The existing network without capacity enhancements has virtually no chance of operating at LOS " $A$ " or " $B$ " for both supply side and demand side. It is currently operating at LOS "E" with a probability close to 0.6 . In other words, the unreliability of the existing network operating at LOS "F" is as high as $40 \%$. 
Table 3. Link flow characteristics of the existing network before capacity enhancements

\begin{tabular}{lrrrrrrr}
\hline Description & Link 1 & Link 2 & Link 3 & Link 4 & Link 5 & Link 6 & Link 7 \\
\hline Link Capacity & 35.00 & 30.00 & 35.00 & 35.00 & 35.00 & 35.00 & 25.00 \\
Mean Link Flow & 31.5898 & 13.7648 & 30.4335 & 14.4753 & 27.9162 & 14.0177 & 14.1579 \\
Standard Deviation & 6.6743 & 6.4495 & 7.5980 & 6.6551 & 7.9469 & 6.5860 & 6.4224 \\
Prob $\left(v_{a} \leq C_{a}\right)$ & 0.7000 & 0.9890 & 0.7510 & 0.9960 & 0.8020 & 0.9970 & 0.9380 \\
\hline
\end{tabular}

Table 4. Capacity reliability and travel time reliability of the existing network before capacity enhancements at various levels of LOS

\begin{tabular}{lc}
\hline Description & Value \\
\hline Capacity Reliability & \\
Probability to operate at least at LOS "A" or "B" & 0.0000 \\
Probability to operate at least at LOS "C" & 0.0440 \\
Probability to operate at least at LOS "D" & 0.0860 \\
Probability to operate at least at LOS "E" & 0.5960 \\
\hline Travel Time Reliability & \\
Probability to operate at least at LOS "A" or "B" & 0.0010 \\
Probability to operate at least at LOS "C" & 0.0470 \\
Probability to operate at least at LOS "D" & 0.0880 \\
Probability to operate at least at LOS "E" & 0.5960 \\
\hline Total Travel Time & 1132.3550 \\
Mean & 277.0954 \\
\hline
\end{tabular}

\section{Convergence characteristics and numerical results}

Without loss of generality, we examine the performance of the proposed BORNDP model and the SMOGA solution procedure under a budget level of 200 and a LOS combination $(\mathrm{C}, \mathrm{AB})$ for the supply-side and demand-side reliability measures. The convergence results of the SMOGA solution procedure are shown in Figures 3 to 5. Figure 3 shows the convergence of the maximum objective function values (i.e., capacity reliability and travel time reliability) of the BORNDP model. The reliability indices steadily increase in the early generations and converge to a near-optimal solution as the generation number increases. Figure 4 shows the 
fitness value of Pareto set and the number of ND solutions in each generation. As the generation number increases, the fitness value of the Pareto set increases steadily, indicating that new ND solutions are found and the Pareto frontier is improving toward the ideal frontier. It should be mentioned that some of the current ND solutions might become inferior and must be discarded from the current set when better ones are found. As shown in Figure 4, the number of ND solutions (represented by the bar graph) does not always increase as the fitness value of the Pareto set improves. Figure 5 depicts the evolution of the Pareto frontier at the $10^{\text {th }}, 20^{\text {th }}, 100^{\text {th }}, 200^{\text {th }}$, and $1000^{\text {th }}$ generation during the SMOGA convergence process. Initially only three ND solutions are generated. As the search proceeds, the number of ND solutions tends to increase with better fitness values as revealed by the tradeoff between the two objective values.

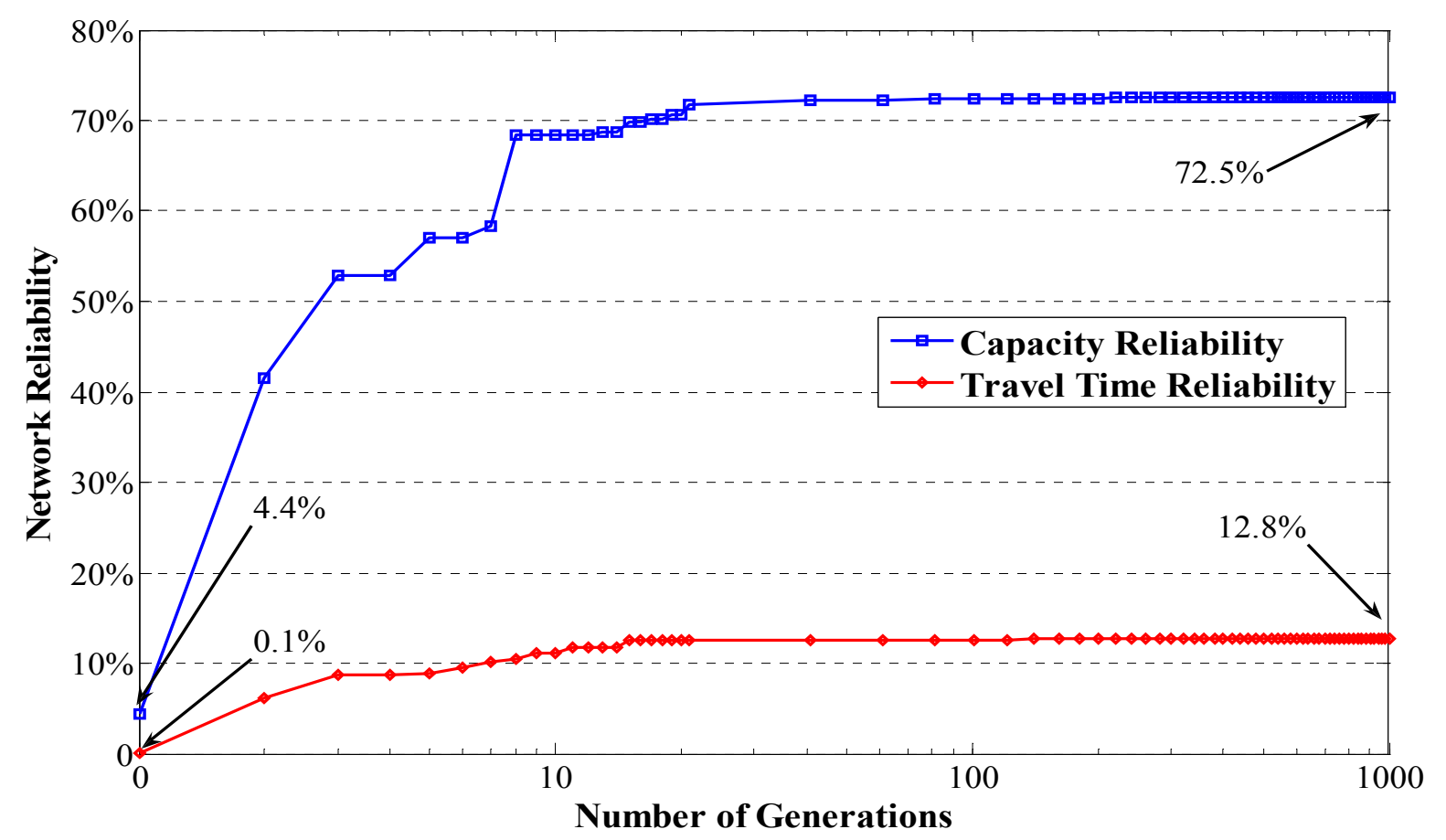

Figure 3. The maximum reliability indices in each generation 


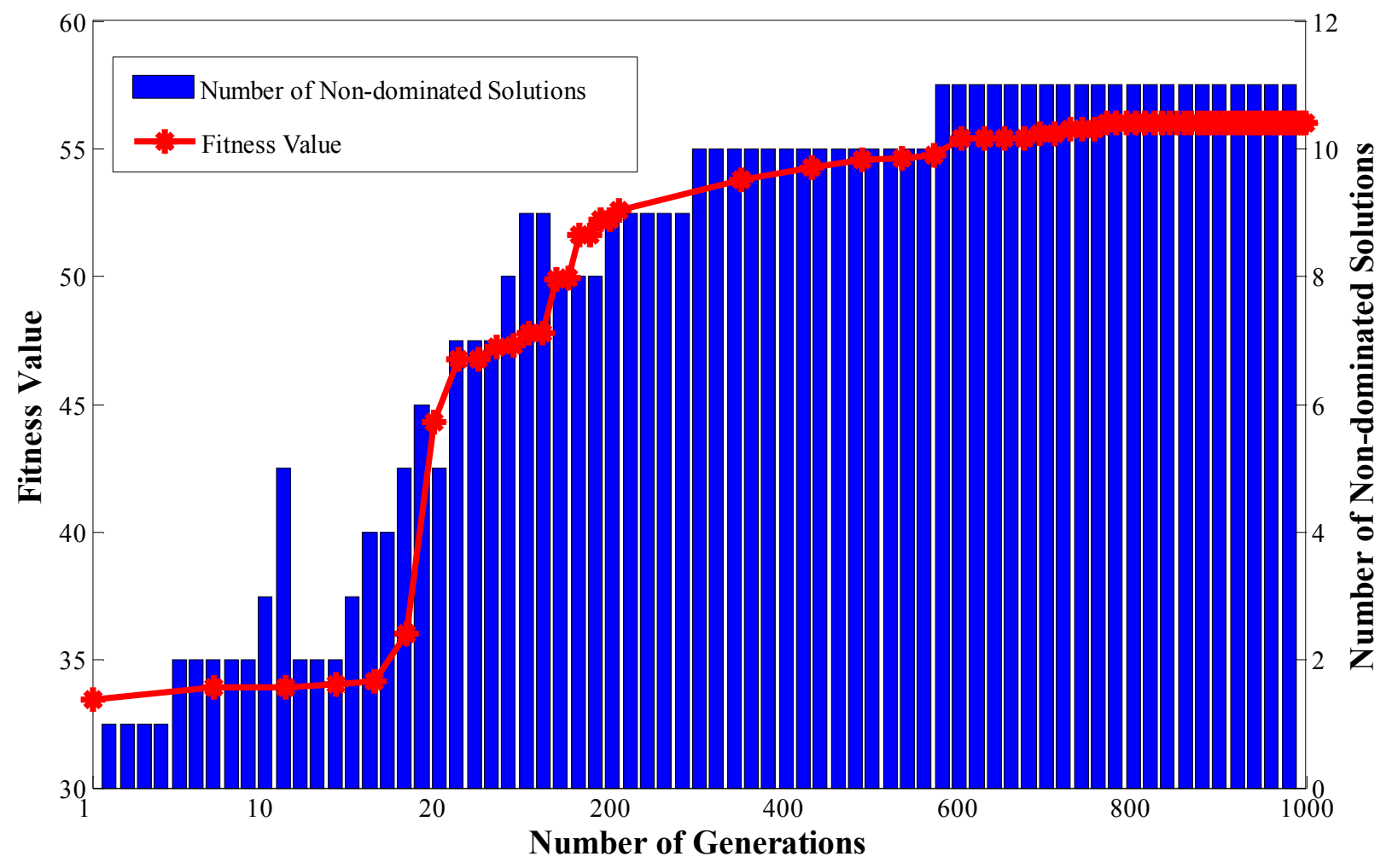

Figure 4. Fitness value of Pareto set and number of nondominated solutions in each generation

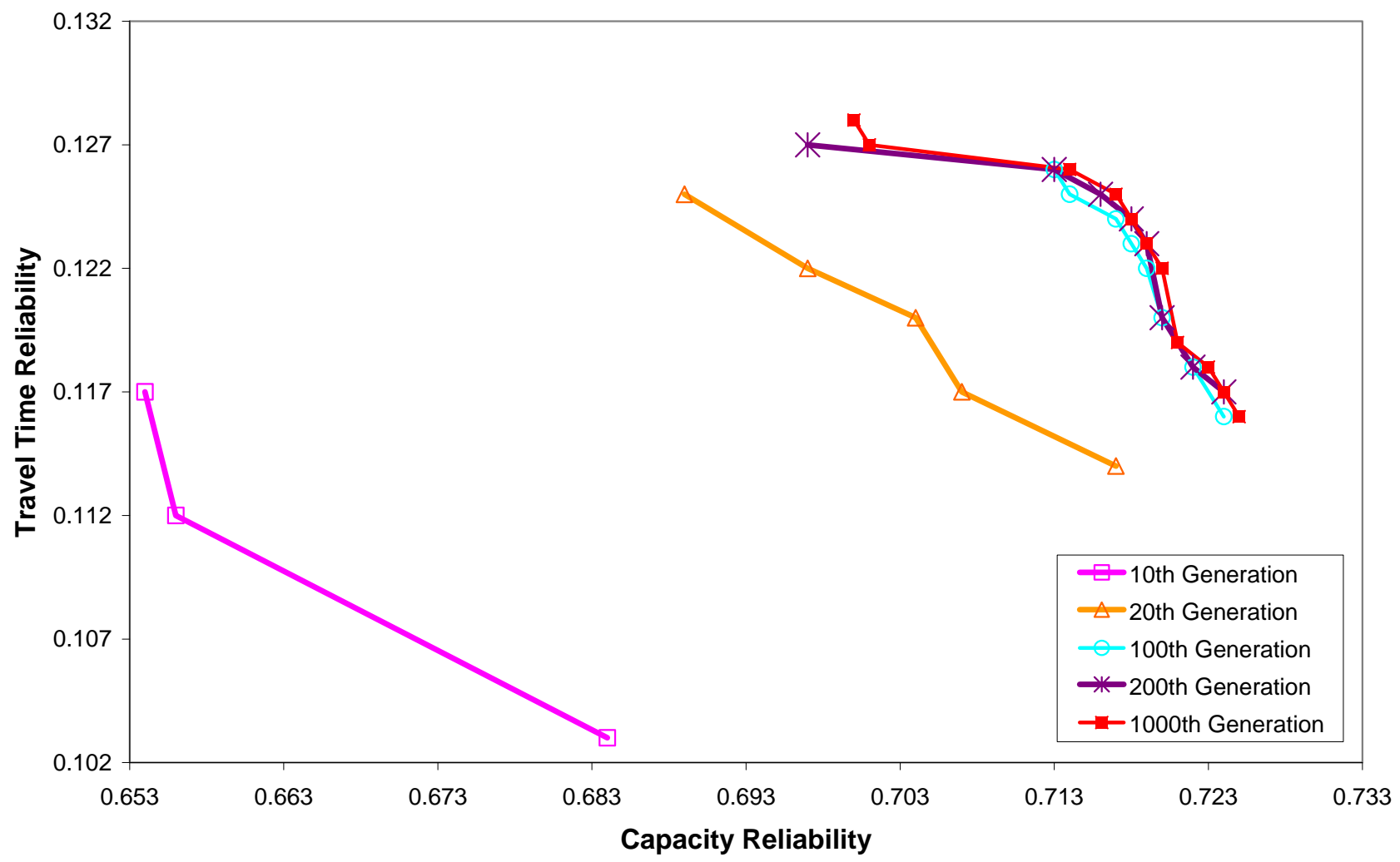

Figure 5. Evolution of the Pareto front for LOS (C, AB) under a budget level of 200 
The numerical results of the BORNDP model are presented in Table 5 and Figure 6. Table 5 presents the ND solutions of optimal capacity enhancements, the construction cost, and the corresponding capacity reliability and travel time reliability. At the final generation, there are 11 ND solutions. Because the objectives are to maximize network reliability, all 11 solutions exhaust the available budget. As shown in Table 5, the ND solutions can provide a significant improvement for both capacity reliability at LOS "C" (from $4.4 \%$ to $72.5 \%$ ) and travel time reliability at LOS " $\mathrm{A}$ " or "B" (from only $0.1 \%$ to $12.8 \%$ ) compared to the donothing case (solution 0). These ND solutions allow the planner to trace the tradeoff between the supply-side and demand-side reliabilities and select an appropriate design plan according to his/her own preference.

Table 5. Non-dominated solutions of LOS (C, AB) under a budget level of 200

\begin{tabular}{ccccccccccc}
\hline \multirow{2}{*}{ Solution } & \multirow{2}{*}{$\begin{array}{c}\text { Capacity } \\
\text { Reliability }\end{array}$} & Travel Time & \multicolumn{9}{c}{ Capacity Expansion } & \multirow{2}{*}{ Cost } \\
\cline { 5 - 9 } & Reliability & Link 1 & Link 2 & Link 3 & Link 4 & Link 5 & Link 6 & Link 7 & \\
\hline $0^{*}$ & 0.0440 & 0.0010 & 0.0000 & 0.0000 & 0.0000 & 0.0000 & 0.0000 & 0.0000 & 0.0000 & 0.00 \\
1 & 0.7000 & 0.1280 & 32.2662 & 0.0020 & 26.2390 & 0.0437 & 5.6731 & 0.0178 & 0.0000 & 199.84 \\
2 & 0.7010 & 0.1270 & 32.2541 & 0.0010 & 26.2850 & 0.0162 & 5.4779 & 0.0078 & 0.0031 & 199.64 \\
3 & 0.7140 & 0.1260 & 32.2529 & 0.0031 & 27.1666 & 0.0000 & 3.5657 & 0.0001 & 0.0012 & 199.91 \\
4 & 0.7170 & 0.1250 & 32.2440 & 0.0000 & 27.4085 & 0.0052 & 3.0526 & 0.0001 & 0.0084 & 200.00 \\
5 & 0.7180 & 0.1240 & 32.2524 & 0.0003 & 27.5690 & 0.0000 & 2.6093 & 0.0000 & 0.0550 & 199.99 \\
6 & 0.7190 & 0.1230 & 32.2066 & 0.0021 & 27.8568 & 0.1194 & 1.9171 & 0.0004 & 0.0536 & 199.99 \\
7 & 0.7200 & 0.1220 & 31.8981 & 0.0004 & 28.1648 & 0.0005 & 1.9209 & 0.0000 & 0.0077 & 199.98 \\
8 & 0.7210 & 0.1190 & 32.0014 & 0.0000 & 28.4639 & 0.0000 & 0.9845 & 0.0000 & 0.0000 & 199.95 \\
9 & 0.7230 & 0.1180 & 31.9757 & 0.0000 & 28.5715 & 0.0088 & 0.7125 & 0.0000 & 0.0272 & 199.90 \\
10 & 0.7240 & 0.1170 & 31.9913 & 0.0227 & 28.7925 & 0.1145 & 0.1386 & 0.0000 & 0.0028 & 200.00 \\
11 & 0.7250 & 0.1160 & 31.6165 & 0.0000 & 29.2004 & 0.0000 & 0.0000 & 0.0000 & 0.0000 & 199.97 \\
\hline
\end{tabular}

\footnotetext{
* Solution without capacity enhancements (i.e., do-nothing case)
} 


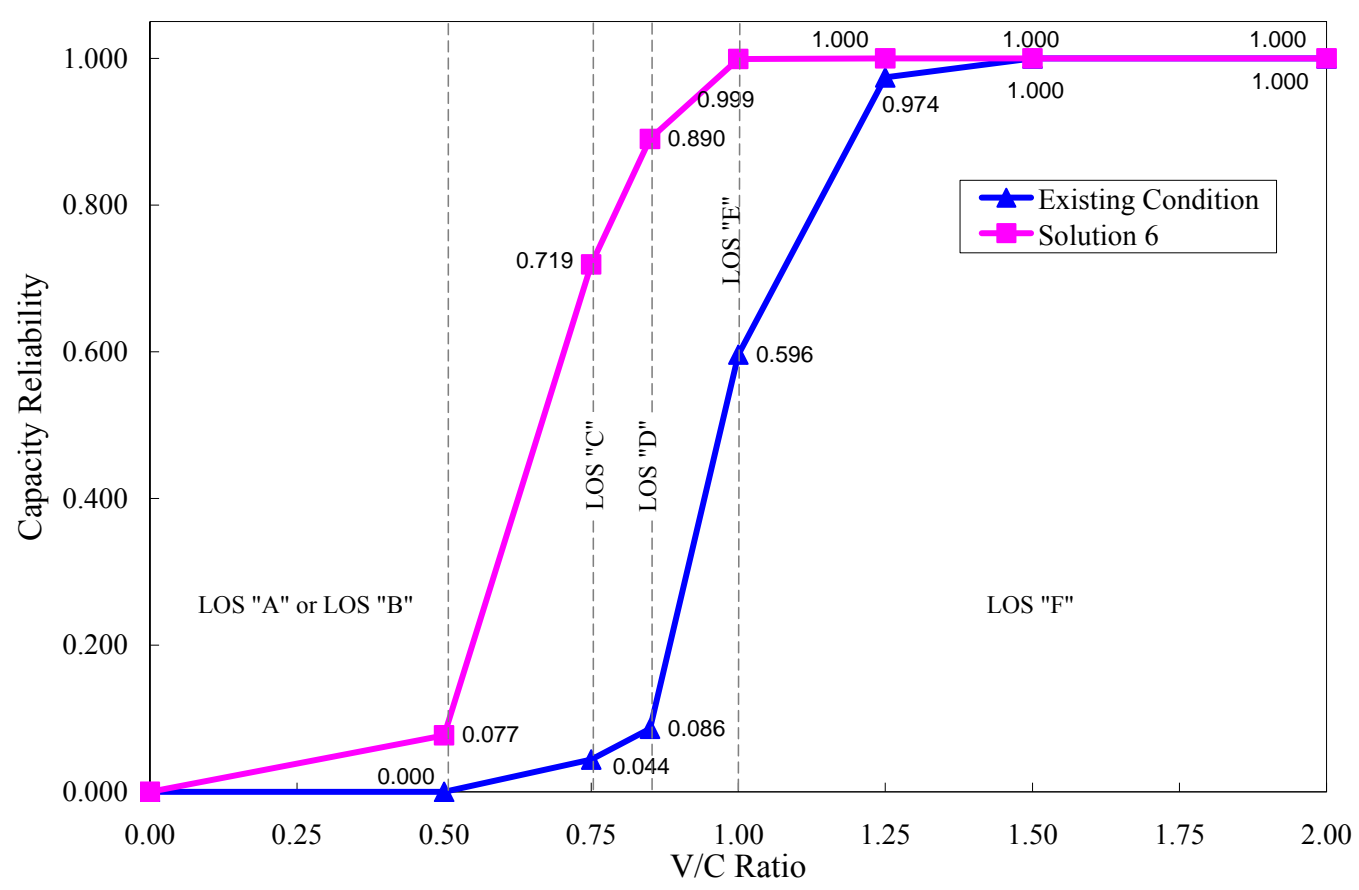

(a) Capacity reliability

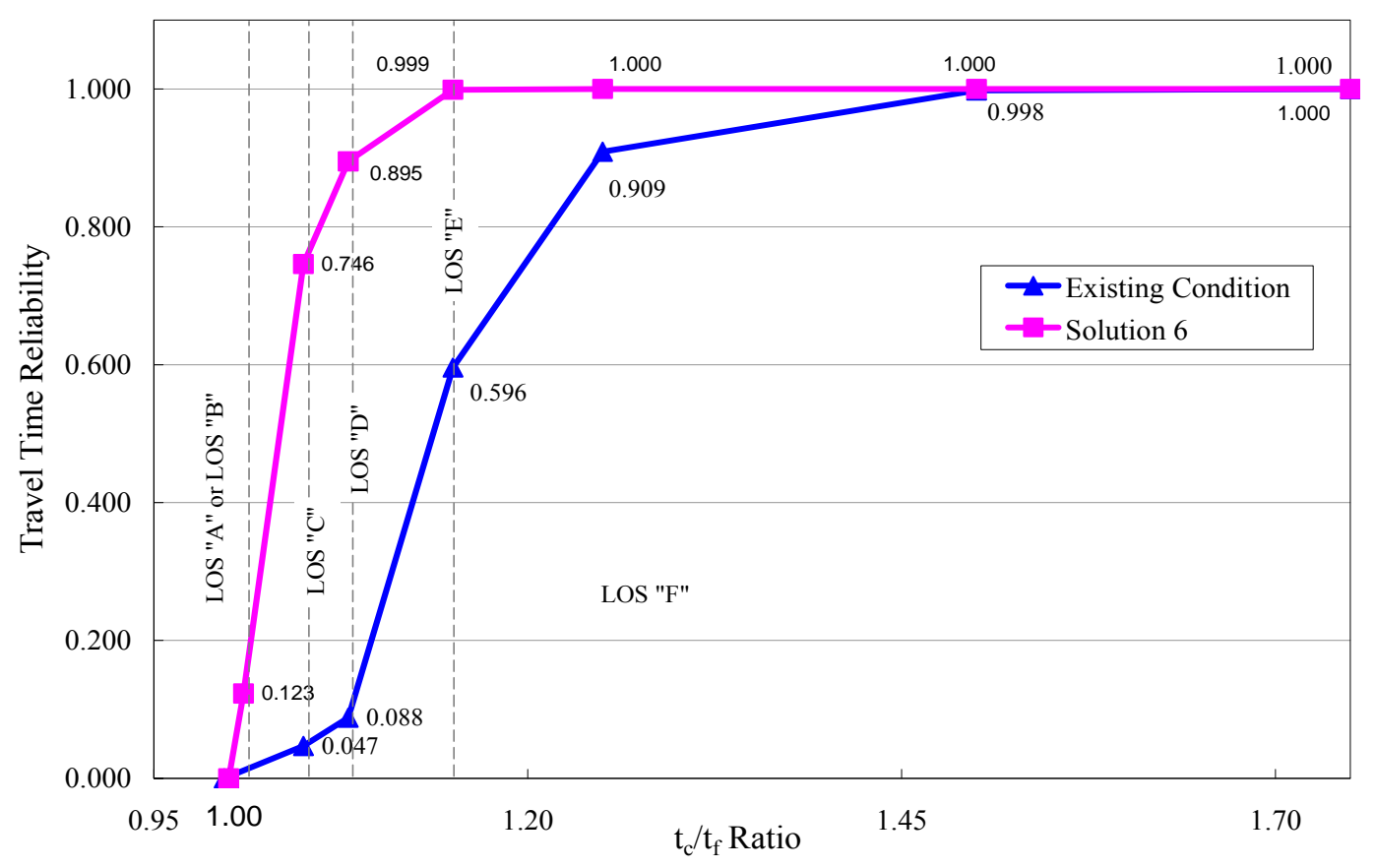

(b) Travel time reliability

Figure 6. Network reliability before and after capacity enhancements of ND solution 6

Capacity reliability and travel time reliability are interdependent and have a complex relationship. For a limited budget and a given LOS combination requirement, the objectives of maximizing capacity reliability and travel time reliability may be conflicting, which can be observed from the Pareto frontier in Figure 5 and the ND solutions in Table 5. Also in Table 
5, it shows that link 1 and link 3 are critical links, which affect the network reliability significantly. These two links provide direct connection for O-D pairs $(1,3)$ and $(2,4)$. Enhancing the capacity of these two links can significantly improve the reliability of these two O-D pairs as well as the overall network reliability. In addition, link 5 seems to also play an important role in ensuring the overall network reliability as well as the tradeoff between the two reliable indices compared to other links due to its key location in the simple network where flow of each O-D pair needs to go through it. Furthermore, enhancements of other links are sometimes necessary to alter the flow pattern to further increase the overall network reliability. This is because the travel cost function we adopted depends on the link capacity. Small capacity expansions on the non-critical links could alleviate the traffic loads of the critical links, which contribute to the overall network reliability. Similar results are also found in the single-objective reliable NDP model (Chootinan et al., 2005).

Using ND solution 6 as an illustration, Figures $6 \mathrm{a}$ and $6 \mathrm{~b}$ show the capacity reliability and travel time reliability compared to the do-nothing case (solution 0 ) for each level of service after capacity enhancements. As can be seen from the reliability curves, both capacity reliability and travel time reliability are improved at all levels of service with capacity enhancements. Significant improvements occur at LOS "C", "D", and "E" for both supplyside and demand-side reliabilities.

\section{Concluding remarks}

In this paper, we provided a state-of-the-art review of transport network design problem (NDP) under uncertainty. In addition, new development on a bi-objective reliable NDP model that considers both capacity reliability and travel time reliability was developed to determine the optimal link capacity enhancements with demand uncertainty. A stochastic multiobjective bi-level programming (SMOBLP) formulation was provided in which the upperlevel subprogram is a bi-objective dependent-chance model that maximizes both supply-side and demand-side reliability performance measures, and the lower-level subprogram is a userequilibrium problem subject to demand uncertainty. A simulation-based multi-objective genetic algorithm (SMOGA) solution procedure was developed to tackle the different complexities involved in solving the SMOBLP formulation. Numerical experiments were conducted to demonstrate the features of the proposed bi-objective reliable NDP model. So far, only demand uncertainty is considered. Future research should also consider the 
degradation of network capacity in designing reliable roadway networks. It is also worthwhile to enhance the behavioral model in the lower-level subprogram by explicitly considering the stochasticity of network flows and risk-averse behavior of road users (e.g., Chen and Zhou, 2010). On the computational side, we plan to enhance the efficiency of the SMOGA solution procedure by incorporating local search, better evolutionary strategies, faster traffic assignment algorithms, and better sampling techniques to speed up the process of finding Pareto optimal solutions. 


\section{Acknowledgements}

The authors are grateful to Prof. Moshe Givoni (Associate Editor of Transport Reviews) and three referees for providing useful comments and suggestions for improving the quality and clarity of the paper. The work of the first author was supported by a CAREER grant from the National Science Foundation of the United States (CMS-0134161), a William Mong Visiting Fellowship to the University of Hong Kong, and a Oriental Scholar Fellowship to Tongji University, the work of the fifth author was supported by two grants from the China National High-Tech Research and Development Project (863 Project) (2007AA11Z206) and the New Century Excellent Talents Program in University (NCET-08-0406), and the work of the sixth author was supported by a grant from the University Research Committee of the University of Hong Kong (10400582/00002771).

\section{Appendix}

This appendix describes the transport network design models under uncertainty. Notation is provided first, followed by the general stochastic bi-level programming formulation, and various upper-level subprograms described in Table 1.

\section{A.1. Notation}

For convenience, the sets, variables, and parameters used throughout the paper are defined as follows:

Sets

A: $\quad$ set of links in the network

$\bar{A}: \quad \quad \quad \quad \quad \quad \quad \quad \quad$ et of design links in the network

$W: \quad$ set of origin-destination $(\mathrm{O}-\mathrm{D})$ pairs

$R_{w}: \quad$ set of paths between O-D pair $w \in W$

\section{Variables}

$f_{r}^{w}: \quad$ flow on path $r \in R_{w}$ between O-D pair $w \in W$

$f: \quad$ vector of path flows $\boldsymbol{f}=\left(\ldots, f_{r}{ }^{w}, \ldots\right)^{\mathrm{T}}$ in the lower-level subprogram

$v_{a}: \quad$ link flow on link $a \in A$ 
$\boldsymbol{v}: \quad$ vector of link flows $\boldsymbol{v}=\left(\ldots, v_{a}, \ldots\right)^{\mathrm{T}}$ in the lower-level subprogram

$u_{a}: \quad$ design variable of link $a \in \bar{A}$

$u_{a}^{\max }: \quad \quad$ upper bound of design variable on link $a \in \bar{A}$

$\boldsymbol{u}$ : $\quad$ vector of link design variables $\boldsymbol{u}=\left(\ldots, u_{a}, \ldots\right)^{\mathrm{T}}$ in the upper-level subprogram

$t_{a}\left(v_{a}, u_{a}\right): \quad$ travel time on link $a \in A$, which is a function of link flow $v_{a}$ and link design variable $u_{a}$

$c_{r}^{w}: \quad$ travel time on path $r \in R_{w}$ between O-D pair $w \in W$

$\pi_{w}: \quad$ minimum travel time between O-D pair $w \in W$

$g_{a}\left(u_{a}\right): \quad$ design cost for link $a \in \bar{A}$

$F(\mathbf{u}, \mathbf{v}(\mathbf{u}, \boldsymbol{\varepsilon})): \quad$ performance measure in the upper-level subprogram

$E(F(\mathbf{u}, \mathbf{v}(\mathbf{u}, \boldsymbol{\varepsilon})))$ : expected value of performance measure in the upper-level subprogram

$V(F(\mathbf{u}, \mathbf{v}(\mathbf{u}, \boldsymbol{\varepsilon})))$ : variance of performance measure in the upper-level subprogram

$\widetilde{F}: \quad$ total performance measure budget in the alpha reliable model

\section{Parameters}

$\begin{array}{ll}\varepsilon: & \text { vector of random variables } \\ Q_{w}: & \text { random demand between O-D pair } w \in W \\ Q: & \text { vector of random variables } Q_{w} \\ q_{w}: & \text { realization of } Q_{w} \\ q: & \text { vector of realization } q_{w} \\ \delta_{a r}^{w}: & \text { a fix path } r \text { of O-D pair } w \text { uses link } a, \text { and } 0 \text { otherwise } \\ \text { B: } & \text { confidence level in the chance-constrained model } \\ \alpha: & \text { threshold of the performance measure in the chance-constrained model and the } \\ \bar{F}: & \text { probability model }\end{array}$

A.2. Stochastic bi-level mathematical program 
The network design problem is generally formulated as a bi-level optimization problem to reflect the different aims of the two decision makers: the network users and the planner. The network users are free to choose their routes such that their individual travel costs are minimized, whereas the planner aims to make the best use of limited resources to optimize one or more network-wide performance measures (e.g., reducing congestion, minimizing environmental impact, maximizing throughputs), while taking into account users' route choice behavior. The general stochastic bi-level mathematical program can be formulated as follows.

$$
\begin{aligned}
& \text { (UP) } \underset{\mathbf{u}}{\operatorname{Minimize}} F(\mathbf{u}, \mathbf{v}(\mathbf{u}, \boldsymbol{\varepsilon})) \\
& \text { subject to } \boldsymbol{G}(\boldsymbol{u}, \boldsymbol{v}(\boldsymbol{u}, \boldsymbol{\varepsilon})) \leq \boldsymbol{0},
\end{aligned}
$$

where $\boldsymbol{v}(\boldsymbol{u}, \boldsymbol{\varepsilon})$ is implicitly defined by:

$$
\begin{aligned}
& \text { (LP) } \underset{v}{\operatorname{Minimize}} f(\boldsymbol{u}, \boldsymbol{v}(\boldsymbol{u}, \boldsymbol{\varepsilon})) \\
& \text { subject to } \boldsymbol{g}(\boldsymbol{u}, \boldsymbol{v}(\boldsymbol{u}, \boldsymbol{\varepsilon})) \leq \boldsymbol{0},
\end{aligned}
$$

where $F$ is the objective function and $\boldsymbol{u}$ is the design vector of the upper-level subprogram (UP), $G$ is the constraint set of UP, $f$ is the objective function and $\boldsymbol{v}(\boldsymbol{u}, \boldsymbol{\varepsilon})$ is the decision variable vector of the lower-level subprogram (LP) as a function of the design vector $(\boldsymbol{u})$ as well as a random vector $(\varepsilon)$, and $g$ is the LP constraint set. The upper-level subprogram describes the leader or planner problem, and the lower-level subprogram represents the follower or user's behavioral problem.

\section{A.3. Transport network design models under uncertainty}

In the transport network design models under uncertainty reviewed in Table 1, the upperlevel subprogram determines the optimal designs $(\boldsymbol{u})$ in a transportation network by using different criterion to optimize a system-wide objective with uncertainty $(\varepsilon)$, while the lowerlevel subprogram determines the route choice behavior (i.e., user equilibrium or stochastic user equilibrium) of network users for a given design vector with uncertainty $(\boldsymbol{v}(\boldsymbol{u}, \boldsymbol{\varepsilon}))$. In this section, we provide the mathematical formulations of the upper-level subprogram used in different transport network design models. The lower-level subprogram using the user equilibrium concept is provided in Eqs. (4a) to (4d). 


\section{A.3.1 Expected value model}

The expected value model is to optimize the expected value of a system-wide performance measure (e.g., total travel time) in Eq. (A.5) subject to the budget constraint in Eq. (A.6) and the limit constraints on the design variables in Eq. (A.7).

$$
\begin{array}{ll}
\min _{u} & E[F(\mathbf{u}, \mathbf{v}(\mathbf{u}, \boldsymbol{\varepsilon}))] \\
\text { s.t. } & \sum_{a \in \bar{A}} g_{a}\left(u_{a}\right) \leq B, \\
& 0 \leq u_{a} \leq u_{a}^{\max }, \quad \forall a \in \bar{A} .
\end{array}
$$

\section{A.3.2 Mean-variance model}

The mean-variance model is to optimize the expected value and variance of a system-wide objective function in Eq. (A.8) subject to the budget constraint in Eq. (A.6) and the limit constraints on the design variables in Eq. (A.7).

$$
\min _{u}\left\{\begin{array}{l}
E[F(\mathbf{u}, \mathbf{v}(\mathbf{u}, \boldsymbol{\varepsilon}))] \\
V[F(\mathbf{u}, \mathbf{v}(\mathbf{u}, \boldsymbol{\varepsilon}))]
\end{array}\right.
$$

s.t. Eq. (A.6) and Eq. (A.7).

The mean-variance model involves two objectives. It belongs to a general class of multiobjective optimization problems. When the objectives are conflicting, there is, in general, no single optimal solution that can simultaneously optimizes all aspects. A solution may be best in one objective, but worst in the others. It is difficult to distinguish the best solution in a multi-objective problem unless a preference structure of all objectives is explicitly defined. According to Gen and Cheng (2000), there are two main approaches to handle this problem: the preference-based approach and the generating approach. The preference-based approach simply converts the multiple objectives into a single objective according to the preference structure supplied by the decision makers. The weighted-sum method is one of the most widely adopted methods used in the preference-based approach. In this method, the objectives are transformed into a composite objective function with predefined weights. Most of the mean-variance NDP models presented in Table 1 adopted the weighted-sum method (see Karroonsonntawong and Waller (2007); Ukkusuri et al. (2007), Gardner et al., 2008; Li et al., 2008; Ng and Waller (2009), Sumalee et al. (2009), and Yin et al. (2009)). For the 
generating approach, the concept of Pareto optimality is adopted. The solution is "Pareto optimal" or "non-dominated" if there were no other feasible solutions that could improve some objectives without worsening at least one other objective. A set of non-dominated solutions generally forms the so-called "Pareto front" or "efficient frontier", which represents the relationship (tradeoff) among multiple objectives. Chen et al., 2003b, 2006b, and Sharma et al. (2009) adopted the generating approach, albeit using different Pareto filters (distancebased method and non-dominated sorting genetic algorithm method), to generate the nondominated solutions of the mean-variance NDP model. For additional information about two approaches for handling multi-objective optimization problems, see Gen and Cheng (2000) and Chootinan et al. (2005a).

\section{A.3.3 Chance constrained model}

The chance constrained model is to optimize the expected value of a system-wide performance in Eq. (A.9) subject to the chance constraint in Eq. (A.10), the budget constraint in Eq. (A.6), and the limit constraints on the design variables in Eq. (A.7).

$$
\begin{array}{ll}
\min _{u} & E[F(\mathbf{u}, \mathbf{v}(\mathbf{u}, \boldsymbol{\varepsilon}))] \\
\text { s.t. } & \operatorname{Pr}(F(\mathbf{u}, \mathbf{v}(\mathbf{u}, \boldsymbol{\varepsilon})) \leq \bar{F}) \geq \alpha,
\end{array}
$$

Eq. (A.6) and Eq. (A.7).

Eq. (A.10) is the chance constraint specified to guarantee the probability that the system-wide performance measure less than the threshold $\bar{F}$ is greater than or equal to the predefined confidence level $\alpha$. Note that the threshold $\bar{F}$ and the confidence level $\alpha$ in the chance constraint (A.10) are both defined by the users. Charnes and Cooper (1959) also suggested using the variance of a system-wide performance measure or the probability of satisfying an aspiration level of the performance measure as the objective function.

\section{A.3.4 Probability model}

The probability model is to optimize the probability of a system-wide performance measure under uncertainty in Eq. (A.11) subject to the budget constraint in Eq. (A.6) and the limit constraints on the design variables in Eq. (A.7). 
$\max _{u} \operatorname{Pr}(F(\mathbf{u}, \mathbf{v}(\mathbf{u}, \boldsymbol{\varepsilon})) \leq \bar{F})$

s.t. $\quad$ Eq. (A.6) and Eq. (A.7).

Eq. (A.11) is the objective function that maximizes the probability that the system-wide performance measure less than the threshold $\bar{F}$ (a user defined value).

\section{A.3.5 Min-max model}

The min-max (or max-min) model is to optimize the worst case of a system-wide performance measure under uncertainty in Eq. (A.12) subject to the budget constraint in Eq. (A.6) and the limit constraints on the design variables in Eq. (A.7).

$\min _{u} \max _{\varepsilon} F(\mathbf{u}, \mathbf{v}(\mathbf{u}, \boldsymbol{\varepsilon}))$

s.t. $\quad$ Eq. (A.6) and Eq. (A.7)

In the robust NDP models by Lou et al. (2009) and Yin et al. (2009), the network improvement scheme is to determine design variables that minimizes the total travel time for the worst-case demand scenario among all realizations of the uncertain demand set. Min-max solutions are known to be conservative by giving up a large amount of efficiency for robustness.

\section{A.3.6 Alpha reliable model}

The alpha reliable NDP model is to optimize $\widetilde{F}$ in Eq. (A.13) required to satisfy the chance constraint in Eq. (A.14), the budget constraint in Eq. (A.6), and the limit constraints on the design variables in Eq. (A.7).

$$
\begin{array}{ll}
\min _{u} & \widetilde{F} \\
\text { s.t. } & \operatorname{Pr}(F(\mathbf{u}, \mathbf{v}(\mathbf{u}, \boldsymbol{\varepsilon})) \leq \widetilde{F}) \geq \alpha,
\end{array}
$$

Eq. (A.6) and Eq. (A.7)

$\widetilde{F}$ is a decision variable defined as the minimum system-wide performance measure required to satisfy the chance constraint at least $\alpha$ times. The alpha reliable NDP model is considered as a variant of the chance constrained model since only the confidence level in Eq. (A.14) is 
user-defined. This model can also be considered as a relaxed min-max model by using the confidence level $\alpha$ to control the risk of not sacrificing too much efficiency for reliability (or robustness). 


\section{References}

Allsop, R.E. (1972) Estimating the traffic capacity of a signalized road junction, Transportation Research 6, pp. 245-255.

Asakura, Y., Kashiwadani, M. (1991) Road network reliability caused by daily fluctuation of traffic flow. In: Proceeding of the $19^{\text {th }}$ PTRC Summer Annual Meeting, Brighton.

Bell, M.G.H., Cassir, C. (2000) Reliability of Transport Networks. (Baldock, England: Research Studies Press Ltd.).

Bell, M.G.H., Cassir, C., Iida, Y., Lam, W.H.K. (1999) A sensitivity-based approach to network reliability assessment. In: Proceedings of the 14th International Symposium on Transportation and Traffic Theory, Jerusalem, pp. 283-300.

Bell, M.G.H., Iida, Y. (1997) Transportation Network Analysis (New York: John Wiley and Sons, Inc).

Bell, M.G.H., Iida, Y. (2003) The Network Reliability of Transport. (Oxford, U.K: Elsevier Science)

Charnes A, Cooper W. (1959) Chance-constrained programming, Management Science, 6(1), 73-79.

Chen, A., Chootinan, P., Wong, S.C. (2006a) New reserve capacity model of a signalcontrolled road network. Transportation Research Record, 1964, pp. 35-41.

Chen, A., Ji, Z., Recker, W. (2002a) Travel time reliability with risk sensitive travelers. Transportation Research Record, 1783, pp. 27-33.

Chen, A., Ji, Z., Recker, W. (2003a) Effect of route choice models on estimation of travel time reliability under demand and supply variations. In The Network Reliability of Transport, Edited by Michael G.H. Bell and Yasunori Iida, (Pergamon: Elsevier Science), pp. 93-118.

Chen, A., Kim, J., Lee, S., Choi, J. (2009) Models and algorithm for stochastic network designs. Tsinghua Science and Technology, 14(3), pp. 341-351.

Chen, A., Kim, J., Lee, S., Kim, Y. (2010) Stochastic multi-objective models for network design problem. Expert Systems with Applications, 37(2), pp. 1608-1619.

Chen, A., Kim, J., Zhou, Z., Chootinan, P. (2007) Alpha reliable network design problem. Transportation Research Record, 2029, pp. 49-57. 
Chen, A., Subprasom, K. (2007) Analysis of regulation and policy of private toll roads in a build-operate-transfer scheme under demand uncertainty. Transportation Research Part A, 41(6), pp. 225-247.

Chen, A., Subprasom, K., Ji, Z. (2003b) Mean-variance model for the build-operate-transfer scheme under demand uncertainty. Transportation Research Record, 1857, pp. 93-101.

Chen, A., Subprasom, K., Ji, Z. (2006b) A simulation-based multi-objective genetic algorithm (SMOGA) for build-operate-transfer network design problem. Optimization and Engineering Journal, 7(3), pp. 225-247.

Chen, A., Tatineni, M., Lee, D.H., Yang H. (2000) Effect of route choice models on estimating network capacity reliability. Transportation Research Record, 1733, pp. 6370 .

Chen, A., Yang, C. (2004) Stochastic transportation network design problem with spatial equity constraint. Transportation Research Record, 1882, pp. 97-104.

Chen, A., Yang, H., Lo, H.K., Tang, W.H. (1999) A capacity related reliability for transportation networks. Journal of Advanced Transportation, 33(2), pp. 183-200.

Chen, A., Yang, H., Lo, H.K., Tang, W.H. (2002a) Capacity reliability of a road network: an assessment methodology and numerical results. Transportation Research Part B, 36(3), pp. 225-252.

Chen, A., Zhou, Z. (2010) The $\alpha$-reliable mean-excess traffic equilibrium model with stochastic travel times. Transportation Research Part B 44(4), pp. 493-513.

Chootinan, P., Chen, A., Yang, H. (2005a) A bi-objective traffic counting location model for origin-destination trip table estimation. Transportmetrica, 1(1), pp. 65-80.

Chootinan, P., Wong, S.C., Chen, A. (2005b) A reliability-based network design problem. Journal of Advanced Transportation, 39 (3), pp. 247-270.

Chow, J.Y.J., Regan, A.C. (2011) Network-based real option models. Transportation Research Part B 45(4), pp. 682-695.

Deb, K., Pratap. A, Agarwal, S., Meyarivan, T. (2002) A fast and elitist multi-objective genetic algorithm: NSGA-II. IEEE Transaction on Evolutionary Computation, 6(2), pp. 181-197.

Dimitriou, L., Stathopoulos, A. (2008) Reliable stochastic design of road network systems. International Journal of Industrial and Systems Engineering 3(5), pp. 549-574.

Gardner, L.M., Unnikrishnan, A., Waller, S.T. (2008) Robust pricing of transportation networks under uncertain demand. Transportation Research Record, 2085, pp. 21-30. 
Gen, M., Cheng, R. (2000) Genetic Algorithms and Engineering Optimization. (New York: John Wiley and Sons, Inc.)

Heydecker, B., Lam, W.H.K., Zhang, N. (2007) Use of travel demand satisfaction to assess road network reliability. Transportmetrica, 3(2), pp. 139-171.

Iida, Y., Wakabayashi, H. (19890 An Approximation Method of Terminal Reliability of a Road Network using Partial Minimal Path and Cut Set. In: Proceeding of the Fifth WCTR, Yokohama, Japan.

Karoonsoontawong, A., Waller, S.T. (2007) Robust dynamic continuous network design problem. Transportation Research Record, 2029, pp. 58-71.

Kurauchi, F., Sumalee, A. (2008) Editorial: Evaluation and enhancement of transport network reliability: Network equilibrium based approach. Journal of Advanced Transportation, 42 (3), pp. 209-212.

Lam, W.H.K. (1999) Special issue: Network reliability and transport modeling. Journal of Advanced Transportation, 33(2), pp. 121-122.

Levinson, D., Liu, H., Bell, M.G.H. (2010) Proceedings of the $4^{\text {th }}$ International Symposium on Transportation Network Reliability, Minnesota, USA.

Li, H., Bliemer, M., Bovy, P. (2008) Network reliability-based optimal toll design. Journal of Advanced Transportation, 42(3), pp. 311-332.

Liu, B. (1999) Uncertainty Programming (New York: John Wiley and Sons, Inc.)

Lo, H.K., Tung Y.K. (2003) Network with degradable links: capacity analysis and design. Transportation Research Part B, 37(4), pp. 345-363.

Lou, Y., Yin, Y., Lawphongpanich, S. (2009) A robust approach to discrete network designs with demand uncertainty. Transportation Research Record, 2090, pp. 86-94.

Markowitz, H. (1927) Mean-Variance Analysis in Portfolio Choice and Capital Markets. New Hope, Pennsylvania.

Ng, M., Waller, S.T. (2009) Reliable system-optimal network design: Convex mean-variance model with implicit chance constraints. Transportation Research Record, 2090, pp. 68-74.

Nicholson, A., Dantas, A. (2004) Proceedings of the $2^{\text {nd }}$ International Symposium on Transportation Network Reliability, Christchurch, New Zealand.

Osyczka, A., Kundu, S. (1995) A new method to solve generalized multicriteria optimization problems using the simple genetic algorithm. Structural Optimization, 10, pp. 94-99.

Schmocker, J.-D., Lo, H.K. (2009) Editorial: Special issue on improving network reliability through ITS technologies. Journal of Intelligent Transportation Systems, 13(1), pp. 1. 
Sharma, S., Ukkusuri, S., Mathew, T. (2009) Pareto optimal multiobjective optimization for robust transportation network design problem. Transportation Research Record, 2090, pp. 95-104.

Sheffi, Y. (1985) Urban Transportation Networks: Equilibrium Analysis with Mathematical Programming Methods. (New Jersey: J.Prentice Hall, England Cliffs)

Sumalee, A., Kurauchi, F. (2006a) Guest editorial: Reliability and emergence issues in transportation network analysis. Network and Spatial Economic, 6(3), pp. 168-172.

Sumalee, A., Kurauchi, F. (2006b) Network capacity reliability analysis considering traffic regulation after a major disaster. Network and Spatial Economic 6(3), pp. 205-219.

Sumalee, A., Luathep, P., Lam, W.H.K., Connors, R.D. (2009) Transport network capacity evaluation and design under demand uncertainty. Transportation Research Record, 2090, pp. 93-101.

Sumalee, A, Watling, D P, Nakayama, S. (2006c) Reliable network design problem: the case with uncertain demand and total travel time reliability. Transportation Research Record, 1964, pp. 81-90.

Ukkusuri, S., Mathew, T., Waller, S.T. (2007) Robust transportation network design under demand uncertainty. Computer-Aided Civil and Infrastructure Engineering, 22(1), pp. 618.

Ukkusuri, S., Patil, G. (2010) Multi-period transportation network design under demand uncertainty. Transportation Research Part B, 43(6), pp. 625-642.

van Zuylen, H. (2007) Proceedings of the $3^{\text {rd }}$ International Symposium on Transportation Network Reliability, Hague, The Netherlands.

Waller, S. T., Ziliaskopoulos, A. K. (2001) Stochastic dynamic network design problem. Transportation Research Record, 1771, pp. 106-113.

Webster, F.V., Cobbe, B.M. (1966) Traffic Signals. Road Research Technical Paper, 56, HMSO, London.

Wong, S.C. (1996) On the reserve capacity of priority junctions and roundabouts. Transportation Research Part B, 30 (6), pp. 441-453.

Wong, S.C., Yang, H. (1997) Reserve capacity of a signal-controlled road network, Transportation Research Part B, 31(5), pp. 397-402.

Yang, H., Bell, M.G.H. (1998) Models and algorithms for road network design: A review and some new developments. Transport Reviews, 18(3), pp. 257-278. 
Yang, H., Lo, K.K, Tang, W. (2000) Combining travel time and capacity reliability for performance measure of a road network. In Reliability of Transport Networks, Edited by M.G.H. Bell and C. Cassir (Baldock, England: Research Studies Press Ltd).

Yim, K.K.W., Wong, S.C., Chen, A., Wong, C.K., Lam, W.H.K. (2011) A reliability-based land use and transportation optimization model. Transportation Research Part C, 19(2), pp. 351-362.

Yin, Y., Ieda, H. (2002) Optimal improvement scheme for network reliability. Transportation Research Record, 1783, pp. 1-6.

Yin, Y., Madanat, S.M., Lu, X.-Y. (2009) Robust improvement schemes for road networks under demand uncertainty. European Journal of Operational Research, 198(2), pp. 470479. 